\title{
Affinity Hemodialysis for Antiviral Therapy with Specific Application to HIV
}

\author{
RICHARD H. TULLIS ${ }^{\mathrm{a}, *}$, DAVID O. SCAMURRA ${ }^{\mathrm{b}}$ and JULIAN L. AMBRUS Jr. ${ }^{\mathrm{c}}$ \\ ${ }^{\mathrm{a} C h i e f ~ S c i e n c e ~ O f f i c e r, ~ A e t h l o n ~ M e d i c a l, ~ I n c ., ~} 3344$ Industrial Court, Suite 1W, San Diego, CA 92121, USA; ${ }^{\mathrm{b}}$ Department of Pathology, Catholic Health \\ System, Buffalo, NY, USA; ${ }^{\mathrm{c} D i v i s i o n}$ of Allergy, Immunology and Rheumatology, University of Buffalo, Buffalo, NY 14203, USA
}

(Received 9 October 2001; In final form 23 May 2002)

\begin{abstract}
We propose an artificial lymph node to improve immune function in fighting viral diseases. The device is based on hemodialysis using a cartridge containing a solid phase affinity resin. Virus capture is mediated by a collection of broad specificity antibodies covalently coupled to agarose. Viral proteins, which can directly damage uninfected cells, are also efficiently removed. Immobilized antisense DNA provides a mechanism to remove infectious viral nucleic acids. Theoretical calculations suggest that the device could effectively remove virus, toxic viral proteins and infectious viral nucleic acids from the blood thereby limiting disease by preventing reinfection of new cells. In the absence of newly infected cells, previously infected cells are cleared by the immune system. For a typical immobilized antibody, calculations predict a pseudo-first order rate of capture $\left(t_{1 / 2} \sim 10 \mathrm{~min}\right)$ with viral load reduction $\sim 660$ fold at equilibrium. Theoretical calculations of a diffusion limited process predict $t_{1 / 2} \sim 2.8 \mathrm{~h}$. Measured transport rates for latex particles in a prototype device are significantly faster than the theoretical diffusion limit suggesting that transport is primarily convective and sufficient to allow rapid virus clearance. Since the device is highly selective it can be used in conjunction with drug therapy and other treatments.
\end{abstract}

Keywords: Virus load; Replication rate; Clearance rate; Affinity hemodialysis; Virus diffusion; Mathematical models

\section{INTRODUCTION}

Antiviral treatments have long been sought to help eradicate important viral diseases. While the body nearly always generates a defensive response, for many pathogenic viruses that response is inadequate to prevent debilitating disease or death. The first effective treatments were vaccines based on weakened or killed viruses. Vaccines such as those developed by Jenner for smallpox, Pasteur for rabies and Salk and Sabin for polio have been highly successful in eradicating viral diseases. More recently, effective vaccines for measles, mumps, rubella and Hepatitis B virus have been developed. However, the search for new vaccines is almost always difficult. Moreover, vaccines for chronic diseases are rare (e.g. HBV vaccine) and to date no successful vaccines exist for chronic diseases caused by highly mutable viruses. For HIV, which introduces up to three mutations in each newly synthesized virus and multiple quasi-species, the search for an effective vaccine is now in its second decade (Gallo and Schupbach, 2000; Menzo et al., 2000; Cohen, 2001).
Although a vaccine may be the best long-term hope for curing chronic viral infections, results to date have been disappointing.

The search for antiviral chemotherapeutics has had less success in spite of intensive research. Conventional therapies using small molecule drugs have grown steadily more effective, particularly those directed against HIV infection and AIDS (Baum et al., 1999; Bower et al., 1999; Clifford et al., 1999; Mocroft et al., 1999). In spite of advances in the treatment of HIV using highly active antiretroviral therapy (HAART), recent studies have shown that live viruses persist in the system even after years of treatment (Chun et al., 1999; Zhang et al., 1999; Ramratnam et al., 2000). Currently $28.5 \%$ of patients are drug resistant, a population that is expected to increase to over $40 \%$ by 2005 (Blower et al., 2001). In addition, latently infected cells and macrophages provide a treatment resistant reservoir that is long lived (Aquaro et al., 1998; Chun and Fauci, 1999). To make things more complicated, host factors also play a role in both disease progression and drug resistance (Cohen et al., 1997).

\footnotetext{
*Corresponding author. Tel./Fax: +1-858-793-8730. E-mail: rhtullis@aethlonmedical.com
} 
As a result, although patient condition is improved, life is prolonged an average of only 1.8 years (Bozzette, 2001) and the treatment ultimately fails due to the development of drug resistance. Recognition of these difficulties has recently led to substantial changes in the Federal Treatment Guidelines on HIV infections (Fauci et al., 2001).

Taken together, these observations indicate that alternative antiviral therapeutic modalities need to be explored. We propose an alternative treatment based on a device that augments the function of the immune system through the physical removal of viruses, toxic viral proteins and potentially infectious viral nucleic acids from the blood of infected patients. Physical removal of pathogens is precisely what biology accomplishes through humoral and cellular immune responses. Antibodies generated to viral antigens bind to the virus and mediate physical clearance from the body, which in turn reduces the reinfection rate. At the same time, previously infected cells are cleared by the immune system, die or become quiescent. When sufficient amounts of the pathogen are cleared from the blood, the viral infection recedes.

Recent drug studies provide evidence that preventing the reinfection of new host cells by circulating infectious virus is an effective means of reducing viral load and inhibiting disease progression. Entry inhibitors, the latest class of new antiviral drugs, are designed to prevent mature, infectious virus from entering new cells. For HIV, the most clinically advanced of the entry inhibitors is T-20, a peptide that binds to gp41 in the viral envelope and prevents fusion of HIV envelope with the host cell membrane (Kilby et al., 1998). A number of other entry inhibitors are currently in or near clinical trials.

The proposed device is a modified hemodialysis cartridge containing immobilized antibodies and antisense DNA. The device functions as an artificial lymph node, increasing the rate of virus clearance and reducing the bystander and superantigen effects of intrinsic viral proteins. The technique is based on hemodialysis, a widely used and highly successful therapy most commonly used to treat kidney failure. The basic cartridge has been in clinical use for over 30 years. The use of multiple antibodies directed against conserved epitopes in the viral coat proteins makes the development of resistant mutations very difficult. Since the affinity matrix elements are covalently immobilized, side effects should be minimal. And since the technique is highly specific, the treatment could be used in conjunction with drug therapy and most other treatments, in contrast to expensive, cumbersome and less effective blood replacement techniques.

In this paper, we describe the principles of the device and discuss the theoretical basis for its operation using HIV as a model infection. While HIV is the focus of this article, we recognize that the technique may be as important in treating fatal, acute viral infections.

\section{DESCRIPTION OF THE AFFINITY HEMODIALYSIS DEVICE}

Our device is based on hemodialysis and a novel hollowfiber affinity dialysis cartridge designed to boost immune system function by efficiently removing viruses and toxic viral proteins from the blood of infected patients. Effective removal of infectious virus from circulation prevents the reinfection of new host cells, analogous to entry inhibitor drugs. As newly infected cells are reduced, previously infected cells die or are cleared by the immune system.

At the same time, viral proteins are reduced, thereby preventing immune cell loss due to the "bystander effect" and superantigenicity. Although there are several theories for the mechanism by which HIV causes AIDS (cf. Cloyd et al., 2000), both the bystander effect and superantigenicity are well documented. HIV envelope proteins have been shown to cause CD4+ $\mathrm{T}$ cells to undergo apoptosis (Koga, 1996; Medina et al., 1999). Binding of gp120 to CD4+ cells in the presence of anti-envelope antibodies and complement opsoninizes the cells, targeting them for clearance (cf. Chaplin, 1999). The combined effect is the destruction of uninfected immune cells known as the "bystander effect" (Ameisen et al., 1995). In addition, HIV envelope proteins function as superantigens, which first overstimulate then deplete B cells (Schnittman et al., 1986; Nair et al., 1988; Muller and Kohler, 1997). Perhaps equally germane, viral surface proteins can directly damage neuronal cells (Krucker et al., 1998; Lipton, 1998; Gray et al., 2001).

Thus the device would function as an artificial lymph node, increasing the rate of virus clearance and reducing the toxic effects of the viral proteins. Moreover, the device is expected to be highly selective for the virus and hence compatible with conventional drug therapy and most other treatments.

The basic platform for the device is hemodialysis. Hemodialysis and plasmapheresis are widely available techniques. While hemodialysis is generally associated with treatment for kidney failure, it has also been used for direct removal of toxins and heavy metals (Ambrus and Horvath, 1987; 1988; Ambrus et al., 1987; Anthone et al., 1995). Circulating immune complexes are also routinely removed by plasmapheresis (Furst et al., 2000). Recent studies have suggested that extracorporeal treatments may have value in treating HIV and AIDS. Simple hemodialysis can produce a small but measurable reduction in viral load (Ahuja et al., 1999). Beretta et al. (2000) report immunologic improvement in partial HAART responders after ex-vivo removal of circulating monocytes. Blick et al. (1998) suggest that passive immunotherapy and frequent plasma donation may delay disease progression in asymptomatic HIV-infected individuals.

For all these reasons, hemodialysis using adsorptive media capable of physically reducing viral load may represent an attractive adjunct to current therapy. While clearly this type of treatment is intended only for patients who are likely to become extremely ill or die as the result 
of infection, it is also clear that these are the diseases whose solution is most highly sought after. Perhaps equally important is the fact that a significant population of HIV+ patients already receive dialysis treatments as a result of HIV-associated nephropathy (Winston and Klotman, 1998; Saha and Agarwal, 2001).

The selectivity of the device is provided by an affinity matrix comprised of a collection of covalently immobilized antibodies directed against conserved epitopes in the viral coat proteins. Immunoaffinity chromatography has been widely employed to purify biological macromolecules as described by Cuatrecasas et al., 1968 (cf. Areson et al., 1980). Large particulate antigens, in particular viruses have been purified in this fashion (Lawrence, 1993; Hauswirth et al., 2000). Studies using affinity methods to remove viruses from blood have typically employed variants of direct binding to ion-exchange resins or immunochromatography in which the blood or plasma is passed directly over the resin. (Terman et al., 1980; Wang and Tsao, 1988; Takashima et al., 1991; Lopukhin Iu et al., 1991; 1992; Tepic and Laissue, 1996; Motomura et al., 1997). While successful in some cases, these methods have not achieved the desired results with virus removal from blood. One plausible explanation for this observation is that many viruses (e.g. HIV) are relatively fragile, shedding viral surface proteins with minimal provocation. As a result, the virus can be stripped from its binding sites by shear forces resulting from fluid flow when blood or plasma is treated directly. In addition, serious side effects such as hemolysis and complement activation may occur when blood cells directly contact the affinity sorbent.

To overcome these difficulties, we use a hollow-fiber dialysis cartridge that contains an affinity resin on the dialysate side of the membrane (Scamurra and Ambrus, 1999). Figure 1 shows how the device is designed to operate.

In the device, the affinity matrix containing immobilized antibodies is located in the free space between the hollow-fibers and set apart from the bulk fluid flow. As blood flows through the hollow-fibers, the virus is transported by a combination of diffusion and convection through pores in the hollow-fibers to reach the affinity matrix. In this situation, antibody-bound viral particles exist outside the blood flow, allowing even relatively weak interactions to capture them. The covalent coupling of antibodies to the affinity matrix prevents them from entering the general circulation, potentially allowing the use of non-human antibodies.

\section{HIV AS A MODEL VIRUS}

HIV is a good model virus for chronic viral disease since a great deal is known about the biology of the virus (cf. Fauci et al., 1996; Gallo and Schupbach, 2000; Braunwald et al., 2001). While it is not the purpose of this article to review these findings, there are a few facts

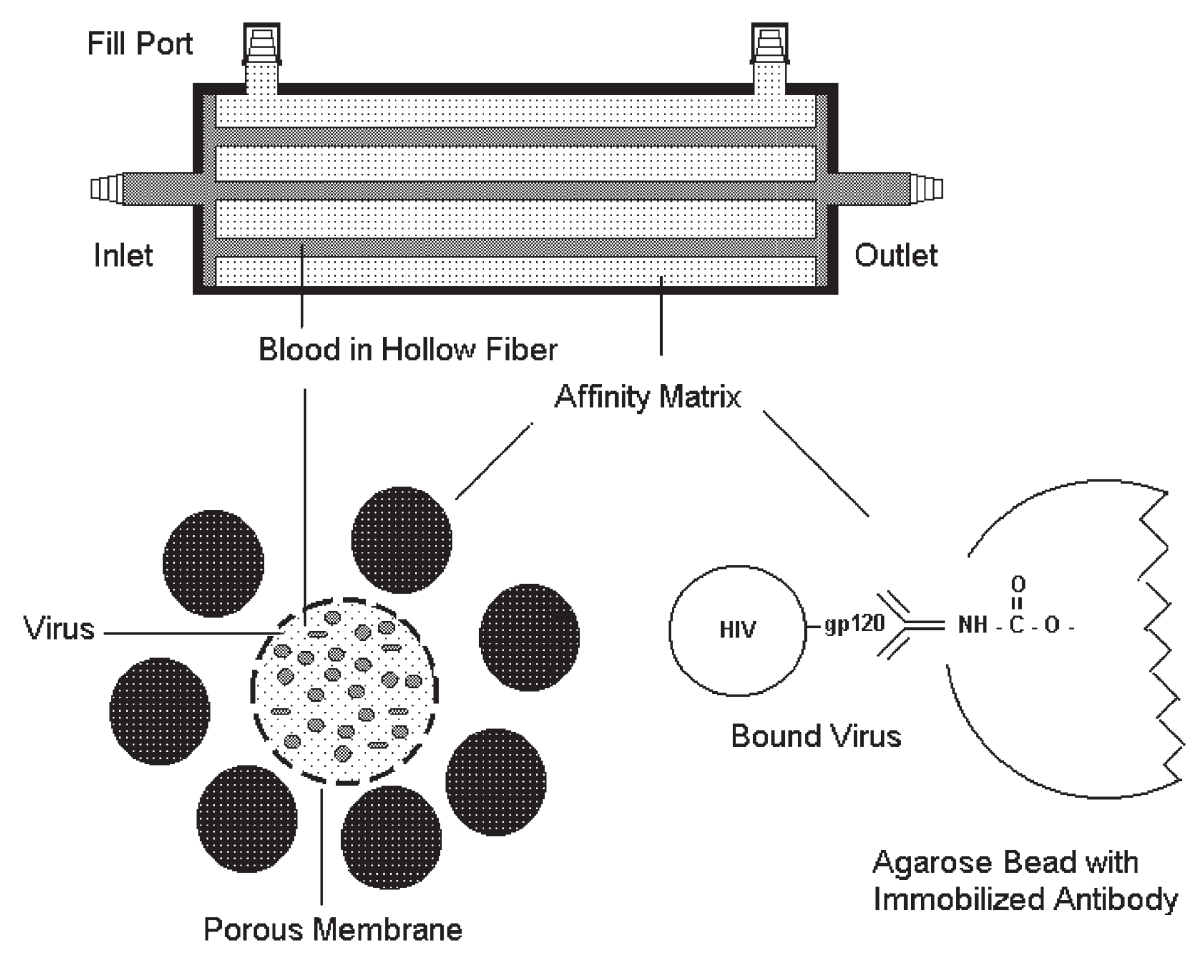

FIGURE 1 Operation of a Hypothetical Artificial Lymph Node Based on an Affinity Hemodialysis Cartridge. The device is a disposable, hollow-fiber hemodialysis cartridge designed to fit on existing hemodialysis machines. The affinity matrix consisting of antibodies covalently-coupled to agarose or glass beads is located in the free space between the hollow-fibers and the dialysate compartment is sealed. Virus and free viral proteins in the blood are transported via convection and diffusion through $200 \mathrm{~nm}$ pores in the hollow fibers to the matrix where they are captured. Formed elements of the blood including red and white cells are excluded. 
worth noting. First, while HIV preferentially infects CD4 $+\mathrm{T}$ cells and macrophages, other cell types can also be infected. These include bone marrow derived stem cells, microglia, fibroblasts, Langerhan's cells, testicular cells and epithelial cells (cf. Pearce-Pratt and Phillips, 1993; Kulkosky et al., 2000). Thus viral reservoirs other than memory $\mathrm{T}$ cells and macrophages may be important. Second, HIV is generally considered non-infectious until the virion has budded off the surface of the infected cell and matured. Maturation may be prevented by protease inhibitors that inhibit viral polyprotein cleavage (Wiegers et al., 1998; Jardine et al., 2000). This may be an important factor in determining the spatial distribution of infectious virus. Third, in blood less than $1 \%$ of CD4+ $\mathrm{T}$ cells are HIV + and a large proportion of the circulating viral particles appear to be non-infectious (Schnittman et al., 1989; Bourinbaiar, 1994). In cell culture, as little as $0.001 \%$ of the virions may be capable of infecting new cells (Layne et al., 1992). These defective particles can also have deleterious effects not associated with virus growth (Kameoka et al., 1997a,b)

The replication rate of HIV in humans is estimated at $10^{10}$ virions per day with a doubling time of $10 \mathrm{~h}$ and a half life in blood of $t_{1 / 2} \sim 6 \mathrm{~h}$ (Ho, 1995; Ho et al., 1995; Wei et al., 1995; Ogg et al., 1998; Little et al., 1999). Infected $\mathrm{T}$ cells have an estimated lifetime of 1.88 days (Lafeuillade et al., 1996a,b). In patients undergoing HAART treatment, the doubling time is estimated at 2-3 days (Neumann et al., 1999). Studies using therapeutic plasma exchange have also been used to estimate the maximal viral doubling times and clearance half times at 3.5-4 and 2h, respectively (Kiprov et al., 1990; Bagnarelli et al., 1997; Ramratnam et al., 1999). In plasma exchange studies, treatment times range from 1 to $2 \mathrm{~h}$. Due to the short duration of treatment, it is likely that the measured rates include a substantial contribution from virus entry into the blood from extravascular reservoirs in addition to new viral replication.

The levels of HIV-1 viral particles in blood strongly correlate with the clinical status of infected patients (Ferre et al., 1995; O'Brien et al., 1996). Typical measured plasma HIV concentrations are on the order of $10^{4}-10^{5}$ viral copies per $\mathrm{ml}$ (cpm). During HAART therapy, the circulating virus population can drop to undetectable amounts $(<100 \mathrm{cpm})$. Even when undetectable by most clinical tests, infectious virus is still present in circulation and can reactivate on removal of the drugs. The decay of latent HIV is inversely correlated with the extent of residual viral replication (Ramratnam et al., 2000) and viral infection is maintained by reinfection of new host cells (Furtado et al., 1999).

Previous studies have suggested that a physical device capable of removing virus would have a beneficial effect. Kapadvanjwala and Sofer (1989) developed a detailed model of the natural history of HIV and the effect of a hypothetical machine that removes the virus from circulation. The model predicts that small increases in the rate of virus removal cause a significant decrease in virus levels. A virus removal device would be even more effective when used in conjunction with drug therapy and other treatments.

More recent models describe the initial infection and establishment of the virus in a steady state (cf. Bonhoeffer et al., 1997; Tuckwell and Le Corfec, 1998; Wodarz et al., 1999). Stafford et al. (2000) provide an explicit model for the early stages of HIV infection and the establishment of the set point or asymptomatic phase is which viral particle production is in steady state with viral particle clearance. The expressions that describe the virus concentration as a function of time are given by a series of non-linear differential equations

$$
\begin{gathered}
\frac{\mathrm{d} T(t)}{\mathrm{d} t}=\lambda-\mathrm{d} T-k T V \\
\frac{\mathrm{d} T^{*}(t)}{\mathrm{d} t}=k T V-\delta T^{*} \\
\frac{\mathrm{d} V(t)}{\mathrm{d} t}=\pi T^{*}-c V
\end{gathered}
$$

where $T$ is the number of CD4 $+\mathrm{T}$ cells (cells/ul), $T^{*}$ concentration of activated CD4 $+\mathrm{T}$ cells (cells/ul), $V$ is the viral load (copies/ul), $\lambda$ is the rate of CD4 $\mathrm{T}$ cell production, $k$ is the rate of infection of T cells, $d$ is the death rate of normal $\mathrm{T}$ cells, $\delta$ is the death rate of productively infected cells, $\pi$ is the rate of virus production (virions/cell/day) and $c$ is the clearance rate constant for the virus.

Using these expressions we calculated the effect of increasing clearance rates on the viral load using a numerical approach. The results, presented graphically in Figure 2, have several interesting features. As Stafford et al. (2000) have already shown, the viral load shows a damped oscillation with time corresponding to changes in viral load shown in patient studies. The results also show that as little as a three-fold increase in clearance rate causes major changes in both the time of appearance of the initial viremic spike and the steady state level of virus. In this model, an increase in viral clearance corresponds to continuous dialysis in a hospital setting $(c=9)$. In practice treatment patterns will be with either continuous (for brief periods of time) or intermittent (a few hours every few days) as is currently the case for kidney dialysis. Continuous dialysis for a period of time early in infection could serve to prevent the establishment of a large viral reservoir, thereby reducing the viral set point and delaying the onset of frank disease.

\section{CONSIDERATIONS IN THE DESIGN OF AN AFFINITY HEMODIALYSIS DEVICE}

The design of an affinity hemodialysis device requires consideration of several key factors. First, the rate and extent of virus binding to the cartridge must be sufficient to remove a major fraction of the viral load in a single 


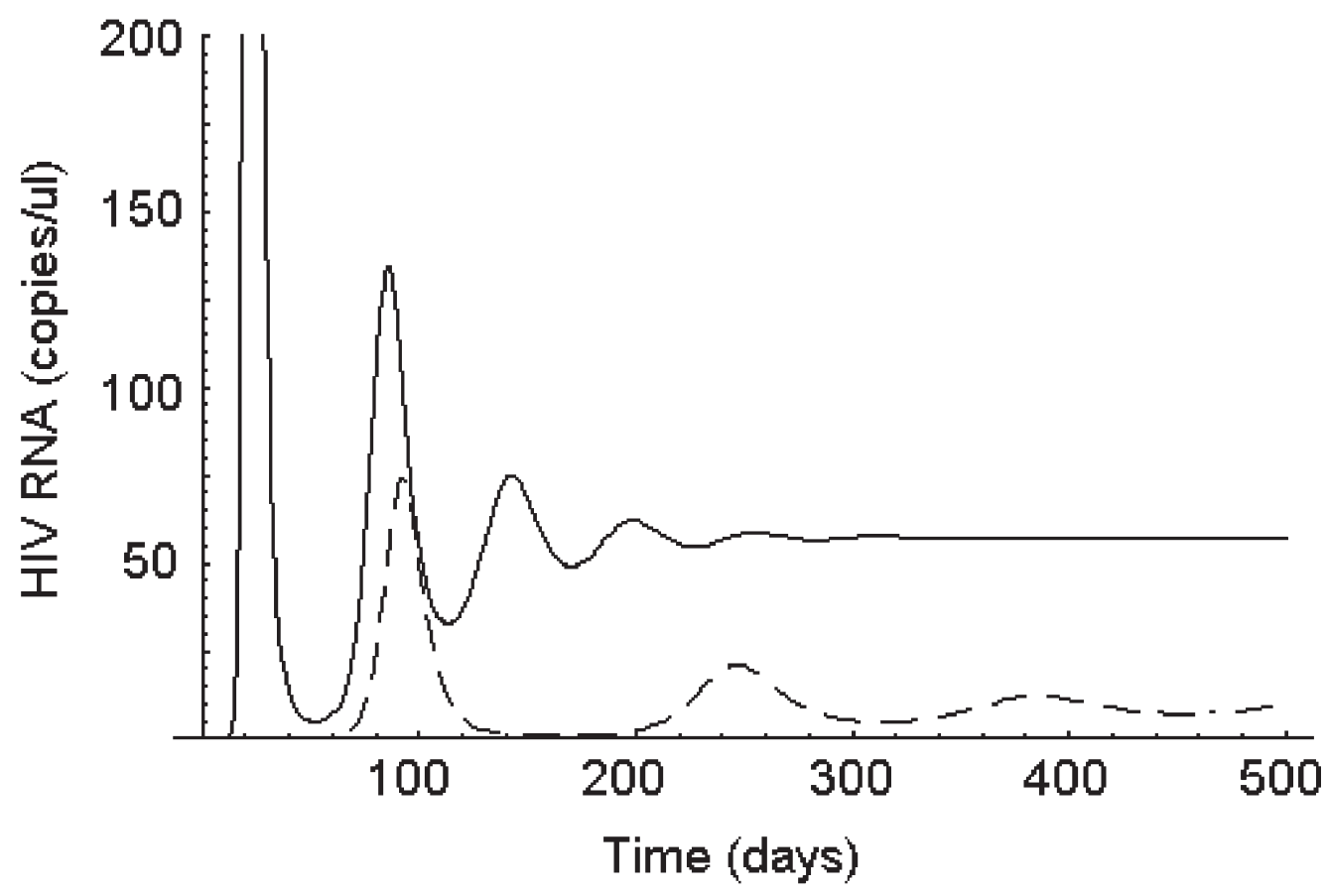

FIGURE 2 Effect of increased rate of HIV viral clearance on viral load. Values calculated from the model of Stafford et al. (2000) comparing normal $(c=3 ;-)$ and $3 \times$ increased rate $(c=9 ;---)$.

treatment. Second, the rate of diffusion and convective transport of the virus across the membrane must be fast enough to allow effective binding to the affinity matrix. And third, the device must effectively reduce viral load without damage to the blood.

\section{RATE AND EXTENT OF VIRUS BINDING TO IMMOBILIZED ANTIBODIES}

The first criterion requires that the binding capacity of the cartridge substantially exceed whole body viral load. To accomplish this, the binding affinity of the immobilized antibodies must be high enough to assure efficient capture of the virus and the kinetics of binding of the virus must be fast enough so that the procedure can be performed in a few hours on the entire blood volume.

The minimum virus-binding capacity of the cartridge is determined by the steady state levels of the virus, which in turn depends on the rates of viral reproduction and clearance. Based on the daily production of $10^{10}$ virions, one would minimally require $1.6 \times 10^{-14}$ moles of specific antibody to bind the virus. The cartridges we envision will contain $10 \mathrm{mg}$ of MAb immobilized on $10 \mathrm{ml}$ of solid support with a maximum capacity of $4 \times 10^{15}$ virions. This capacity is 400,000 times higher than the capacity needed to remove the total daily production of the virus. Given that good monoclonals have binding affinities $\mathrm{Ka} \sim 10^{10}$ high capture efficiencies can be expected. Given a reasonable concentration of $\mathrm{MAb}$ within the cartridge of $7 \times 10^{-8} \mathrm{M}$, the equilibrium concentration of the free virus would be $1.3 \times 10^{-18} \mathrm{M}$ vs. an initial concentration of $8 \times 10^{-16} \mathrm{M}$. At equilibrium, this would result in 660 fold reduction in both virus concentration and free viral surface proteins (e.g. gp120).

For efficient capture, the rate of the reaction is also important. The kinetics of virus binding must be fast enough so that the procedure can be performed quickly. The influence of immobilization on antibody reaction kinetics has been studied in detail (Nygren et al., 1987). Typical monoclonal antibodies have on-rate constants averaging $k_{\text {on }} \sim 10^{5} \mathrm{M}^{-1} \mathrm{~s}^{-1}$. Since the antiviral antibodies are in vast excess over circulating virus, the reaction becomes pseudo-first order. Using the conditions given above, we can calculate a $t_{1 / 2} \sim 100 \mathrm{~s}$ for the reaction. Under these conditions, binding should be effectively complete in $17 \mathrm{~min}$ (10 half-lives).

This analysis has an important corollary in that since the reaction is pseudo-first order, the half-reaction time depends only on the initial concentration of the immobilized antibody and is independent of the concentration of the virus. Thus if the rate limiting step is virus binding to the affinity matrix, even at the lowest virus concentrations, $50 \%$ will be removed in $\sim 2 \mathrm{~min}$. This should be true even in cases where the concentration of the virus is below the limit of detection of current testing.

Another consequence of viral infection is the presence of infectious viral nucleic acids derived from cell lysis. Many viral nucleic acids are known to be directly infectious. Since nucleases are widespread in nature and occur in measurable concentrations in blood, it would seem unlikely that the concentrations of viral nucleic acids in blood would be significant. However, evidence 
is accumulating that circulating free DNA and RNA are present in significant amounts in plasma and serum. In fact, the initial observations of cell free circulating RNA and DNA were made by Mandel and Metais over 50 years ago. Current estimates place normal circulating DNA levels at $13 \mathrm{ng} / \mathrm{ml}$ with values climbing to over $180 \mathrm{ng} / \mathrm{ml}$ in some disease states (Anker, 2000). RNAs of several types including viral messenger RNAs have also been found (Su et al., 2001).

While current evidence suggests that HIV requires a complete, mature virion for infectivity, it would not be surprising to learn that HIV RNA has some level of direct infectivity. In order to prevent any potentially infectious viral nucleic acid from contributing to the spread of the disease, we have incorporated into the design of the device an antisense DNA affinity matrix to capture viral RNA and RNA fragments.

The rate of capture of free viral RNA or DNA can be predicted (cf. Meinkoth and Wahl, 1984). The rate expression for a pseudo-first order hybridization reaction (with the capture strand in sequence excess) is given by

$$
C_{\mathrm{o}} t_{1 / 2}=\frac{1.98 \times 10^{-6} N}{L^{0.5}}
$$

where $C_{\mathrm{o}}$ is the concentration of the oligonucleotide (in moles nucleotide/l), $N$ is the complexity of the DNA and $L$ is the length of the DNA in bases. Using this formula, one can estimate the half-time for a hybridization capture under essentially physiological conditions. For a 20 base capture probe at $50 \mathrm{ug} / \mathrm{ml}$, the calculated $t_{1 / 2}$ is $\sim 0.056 \mathrm{~s}$. Thus, on the basis of direct reaction rates it is reasonable to expect that an affinity hemodialysis cartridge could efficiently remove circulating viral nucleic acids in times on the order of minutes.

\section{HEMODIALYSIS AND VIRAL DIFFUSION}

The second design consideration is that the transport of the virus through the pores in the membrane be fast enough to allow efficient removal. Diffusion is typically a slow process and is often rate limiting in chemical and enzymatic reactions (Cussler, 1998). Diffusion theory predicts an inverse proportionality to the square root of the molecular weight. On this basis alone, viruses will diffuse 5-10 times more slowly than most proteins. Thus transport of the virus may become rate limiting. Virus transport through membranes has been the subject of several mathematical studies related to the permeability of gloves and condoms (Davis, 1998).

In hemodialysis, blood flows through $200 \mu$ capillaries at a linear flow rate $\sim 1 \mathrm{~cm} / \mathrm{min}$. Under these conditions, viral particles in the blood are likely to be entrained in fluid flow through the lumen of the fibers with only a small portion retained near the walls in a relatively stagnant boundary layer. On the other hand, red blood cells and lymphocytes tend to push the smaller viral particles to the periphery due to volume exclusion effects. Within the lumen, viral particles are transported through $200 \mathrm{~nm}$ pores in the membrane by a combination of thermal diffusion and convection driven by pressure differentials. When the virus enters the pores, diffusion effects may become most important. Since the pores are on average $40 \mu$ long and only $200 \mathrm{~nm}$ wide, virus particles in the pores can also diffuse to the walls and interact with the membrane.

In order to determine the effects of diffusion on the process, we first calculated the rate of approach to equilibrium based on the diffusion of a $100 \mathrm{~nm}$ particle across a porous membrane into an infinitely large dialysis reservoir $(V 1 \gg V 2)$ using the formula $\Delta C_{t}=\Delta C_{\mathrm{o}} e-$ $D \beta t$ where $\Delta C_{t}$ is the concentration difference across the membrane at time $t, D_{\mathrm{o}}$ is the diffusion coefficient at infinite dilution and $\beta=A / \lambda^{*}\left(1 / V_{\text {in }}+1 / V_{\text {out }}\right)$ where $A$ is the surface area of the membrane in contact with the fluid, $\lambda$ is the length of the diffusion path (i.e. the width of the membrane) and $V$ is the volume of the solution on either side of the membrane (Cussler, 1998). We model the effect of irreversible capture of the virus by setting volume inside the cartridge to be very much larger than the volume of the solution to be dialyzed $\left(V_{\text {in }} \gg V_{\text {out }}\right)$ which reduces $\beta$ to $A / \lambda^{*}\left(1 / V_{\text {out }}\right)$.

For purposes of calculation we have used the properties of a typical hemodialysis cartridge. $D_{\mathrm{o}}$ for HIV was estimated at $2.9 \times 10^{-8} \mathrm{~cm}^{2} \mathrm{~s}^{-1}$ based on a spherical virus with a diameter of $110 \mathrm{~nm}$. The results presented graphically in Figure 3 gave an estimated $t_{1 / 2}$ of 2.5 or $11 \mathrm{~h}$ to $95 \%$ equilibration. Thus in a diffusion limited

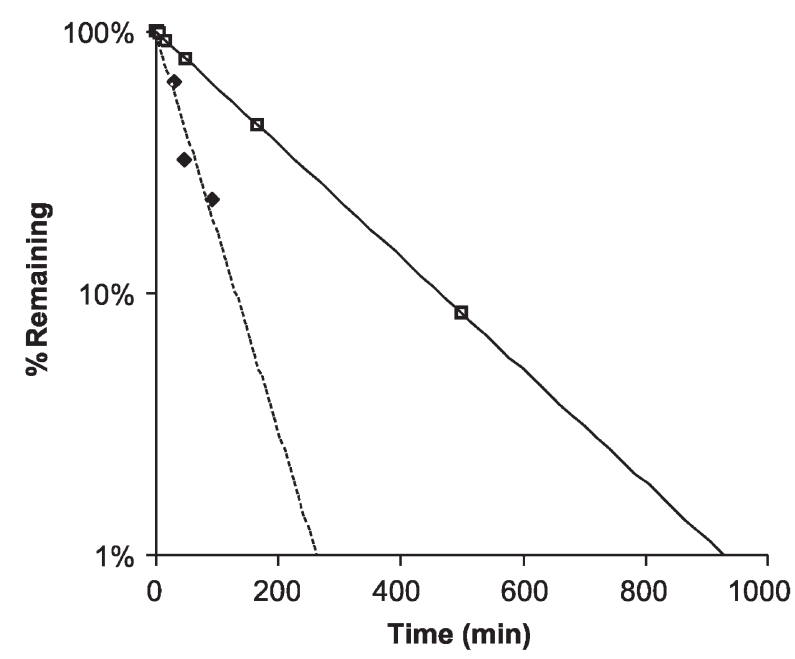

FIGURE 3 Transport of $100 \mathrm{~nm}$ Fluorescent Latex beads in a Hollowfiber Device vs Calculated Diffusion. The cartridge was $\sim 0.5 \mathrm{~cm} \times$ $10 \mathrm{~cm}$ and containing polyethersulfone hollow fibers $(500 \mu \mathrm{ID} ; 40 \mu$ wall thickness; nominal pore size $500 \mathrm{~nm}$; estimated membrane surface area of $5 \mathrm{~cm}^{2}$; intraluminal volume $80 \mathrm{ul}$; extraluminal volume $450 \mathrm{ul}$ ) Circulating volume was $20 \mathrm{ml}$ containing $0.02 \% 1 \mathrm{u}$ red and $0.04 \%$ $100 \mathrm{~nm}$ green fluorescent latex beads. For calculation of the rate of irreversible diffusion parameters of the device were $A=5 \mathrm{~cm}^{2}, \lambda=$ $40 \mu, V_{\text {in }}=100 \mathrm{ml}, V_{\text {out }}=51$ and $C_{\mathrm{o}}=10^{5}$ virions $/ \mathrm{ml} . D_{\mathrm{o}}$ for the $100 \mathrm{~nm}$ beads was $2.9 \times 10^{-8} \mathrm{~cm}^{2} \mathrm{~s}^{-1}$ (same as HIV). Measured $\bullet-$ calculated $\square-\square$. 
device with essentially irreversible virus binding, viral load would be reduced 20 fold in $11 \mathrm{~h}$.

In a hollow fiber dialysis device, diffusion may be less important than convection. In order to test the actual performance of the device we performed a model experiment to measure the rate of transport of $100 \mathrm{~nm}$ carboxylate-modified fluorescent latex beads across a $500 \mathrm{~nm}$ pore polyethersulfone hollow-fiber membrane. Carboxylate modified beads were used to mimic a virus particle with a net negative charge at physiological $\mathrm{pH}$. In this experiment, $1000 \mathrm{~nm}$ red beads and $100 \mathrm{~nm}$ green beads were mixed in a 1:1 ratio in PBS and the diffusion rate observed in a $0.5 \mathrm{ml}$ volume hollow-fiber dialysis device. Hemodiafiltration showed that the membranes in the device allowed $0.1 \mathrm{u}$ green particles to pass freely while completely excluding the $1 \mathrm{u}$ red particles, indicating that the membranes were intact and operating properly.

With the dialysate compartment sealed, the red and green bead mixture was circulated through the device at a flow rate of $10-20 \mathrm{ml} / \mathrm{min}$. At intervals, the pump was stopped and the cartridge isolated from the external solution by means of the shutoff valves. The external compartment, containing any beads that had entered, was then flushed with PBS and the concentration of the green and red beads noted. The valves were then restored to the original configuration condition and flow resumed. The results, also shown in Figure 3, showed a rapid accumulation of $100 \mathrm{~nm}$ green beads in the dialysis compartment and depletion from the external circulation. Accumulation appeared to be virtually complete in $90 \mathrm{~min}$ with a $t_{1 / 2} \sim 30 \mathrm{~min}$. Since this is substantially faster than the estimated rate of accumulation due to diffusion alone, particle transport in this system must involve a large convection component driven by trans-membrane pressure differentials.

To further explore the properties of the affinity hemodialysis device, we measured the capture of replication defective HIV from cell culture media. First we constructed an antibody capture matrix in which a mixture of anti-gp-120 antibodies were bound to protein $\mathrm{G}$ agarose and subsequently immobilized with disuccinimidyl suberimidate. A hemopurifier cartridge was then constructed using the Microkros cartridge described in the section above and loaded in the extraluminal space with the immobilized antibody matrix. As shown in Figure 4, passaging the virus isolated from the HL $2 / 3$ cell culture fluid from through the cartridge resulted in a rapid decrease in virus as judged by p24 ELISA. After $1 \mathrm{~h}$ approximately $82 \%$ of the virus was removed vs. $12 \%$ for the control. Similar results were obtained with gp120 from the same cell culture system (data not shown). A more detailed analysis including in depth experimental details and results have been published elsewhere.

Thus, measured transport rates for fluorescent latex particles and viral capture from cell culture fluids support the contention that hemodialysis can be an effective means of capturing circulating virus from model fluids.
Further experiments will be required to confirm the efficiency of the device against natural virus populations in blood.

\section{POTENTIAL PROBLEMS}

There are several potential problems which confront the design of artificial organs in general, and artificial lymph nodes in particular. Humoral antibodies specific to the virus could bind to viral surface proteins and block viral capture. Viral mutations might also allow the virus to evade capture. In addition to the biology of the host virus interactions, the device itself could generate undesirable host responses.

In almost every instance of viral infection, the body generates antibodies against viral proteins many of which target the virus coat. For HIV, these antibodies are generally of non-neutralizing and inadequate in concentration to control the infection. In order to overcome this challenge, it is necessary to select antibodies that have higher affinity for the virus than those generated by the patient. It is also possible to genetically engineer antibodies with very high affinity constants as well as significantly enhanced on rates.

Similarly, viral mutations can alter targeted epitopes allowing the virus to evade capture. In order to prevent the development of resistant mutations, we propose incorporating a collection of broad-spectrum antibodies, which react with all known viral clades. Since HIV diagnostics face the same challenge, many broad-spectrum antibodies are already known which would be directly useful.

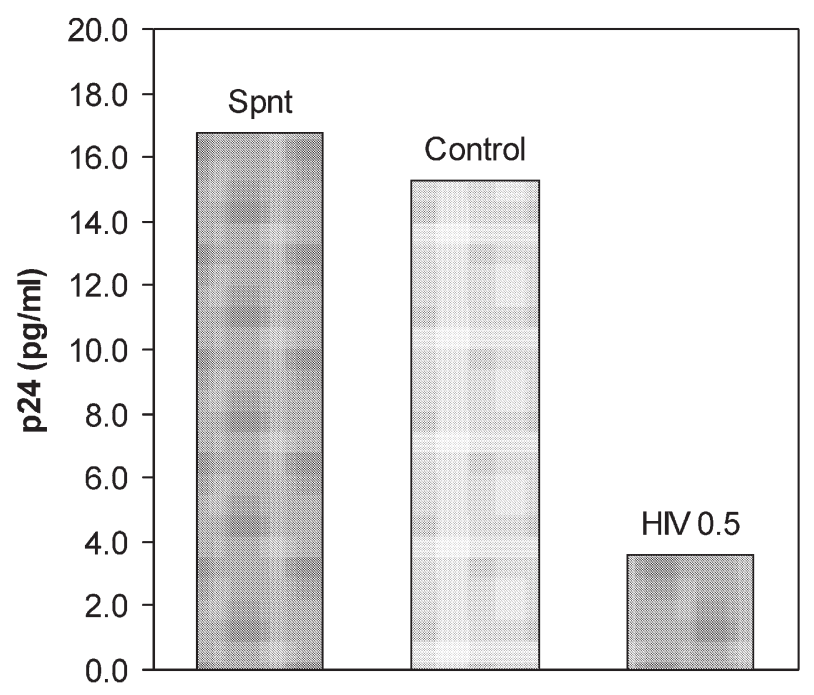

FIGURE 4 Capture and removal of HIV from HL2/3 Cell Culture Supernatants Using an Affinity Hemodialysis Device. The cartridge was as described in Figure 3 modified to contain $\sim 0.5 \mathrm{ml}$ a mixture of antigp120 monoclonal antibodies covalently crosslinked to protein $\mathrm{G}$ agarose using DSS (disuccinimidyl suberimidate). HL 2/3 cell culture supernatant was manually passed over the cartridge for $1 \mathrm{~h}$. p24 gag was then measured by quantitative ELISA (NEN-DuPont). Control=albumin Sepharose. Spnt $=$ HL 2/3 cell culture supernatant before treatment. 
Clearly, virus removal will provide selective pressure toward resistant mutants just as it does with drugs and natural antibodies. However, it is a simple matter to replace antibodies in the cartridge as opposed to the development and testing of a new drug, primarily because the antibodies in the cartridge are covalently immobilized and thus prevented from entering the general circulation. This flexibility makes it possible to consider actually tailoring the cartridge to the individual patient.

Another potential problem is protein leakage from the device. Antibodies injected directly into the blood stream are already used for therapeutic purposes. We have selected a covalent coupling methodology that is highly resistant to leakage. Thus, the relatively small amounts of protein or peptide entering the blood stream from the device should not present an insurmountable problem.

Cartridge mediated damage to formed blood cells and the generation of cellular activation factors including complement is a continuing concern in hemodialysis. Early on it was observed that blood contact with synthetic membranes resulted in hemolysis, leucopoenia and complement activation resulting in severe complications and death for some patients. More modern membrane formulations have substantially decreased these side effects. While some issues such as $\beta 2$-microglobulin build-up remain a problem, these cartridges have been FDA approved and generally considered safe and effective in over 30 years of use.

Complement activation is perhaps the most likely problem for a cartridge of the type we have proposed. Complement activation is stimulated by the presence of immobilized antibodies and antibody complexes. The process is initiated by complement binding to the Fc region of antibodies. However, devices that trap antibody complexes are already in general use. One such device is the Prosorba column developed by Cypress Biosciences and currently marketed as an FDA approved device for the removal of antibody complexes from the blood of patients with severe, non-responsive forms of rheumatoid arthritis (Furst et al., 2000). The device consists of Protein A covalently linked to diatomaceous earth (primarily silica) enclosed in a plastic cartridge. The device removes large amount of immunoglobulins and antibody complexes without harmful levels of complement activation. Thus it is likely that the proposed device, which is very similar in structure, would not be any less safe.

\section{CONCLUSIONS}

Chronic viruses present a continuing challenge to current drugs and vaccines. We propose a device based on hemodialysis and immunoaffinity capture designed to augment the function of the immune system to treat viral infections. The device is highly selective and can be used in conjunction with other treatments. Based on the available data, it is likely that an effective affinity hemodialysis device can be developed which effectively and safely removes pathogenic viruses and viral proteins directly from the blood.

\section{References}

Ahuja, T., Niaz, N., Velasco, A., Watts, B. and Paar, D. (1999) "Effects of hemodialysis and antiretroviral therapy on plasma viral load in HIV-1 infected hemodialysis patients", Clinical Nephrology 51, 40-44.

Ambrus, C. and Horvath, C. (1987) "Blood purification", US Patent $4,714,556$.

Ambrus, C. and Horvath, C. (1988) "Blood purification", US Patent $4,787,974$.

Ambrus, C., Anthone, S., Horvath, C., Kalghatgi, K., Lele, A.S., Eapen, G., Ambrus, J.L., Ryan, A.J. and Li, P. (1987) "Extracorporeal enzyme reactors for depletion of phenylalanine in phenylketonuria", Annals of Internal Medicine 106, 531-537.

Ameisen, J.C., Estaquier, J., Idziorek, T. and De Bels, F. (1995) "Programmed cell death and AIDS pathogenesis, significance and potential mechanisms", Current Topics in Microbiology and Immunology 200, 195-211.

Anker, P. (2000). "Quantitative aspects of plasma/serum DNA in cancer patients". Anker, P. and Stroun, M. (eds.) "Circulating nucleic acids in plasma or serum". Annals of the New York Academy of Science, 906 (2000) 5-7.

Anthone, S., Ambrus, C., Kohli, R., Anthone, R., Stadler, A., Stadler, I. and Vladutiu, A. (1995) "Treatment of aluminum overload using a cartridge with immobilized desferrioxamine", Journal of the American Society of Nephrology 6, 1271-1277.

Aquaro, S., Calio, R., Balestra, E., Bagnarelli, P., Cenci, A., Bertoli, A., Tavazzi, B., Di Pierro, D., Francesconi, M., Abdelahad, D. and Perno, C.F. (1998) "Clinical implications of HIV dynamics and drug resistance in macrophages", Journal of Biological Regulatory and Homeostatic Agents 12, 23-27.

Areson, P., Charm, S. and Wong, B.L. (1980) "Antibody affinity columns", Biotechnology and Bioengineering 22, 2207-2217.

Bagnarelli, P., Candela, M., Valenza, A., Manzin, A., Solforosi, L., Mazzola, F., Butini, L., Montroni, M., Gabrielli, A., Varaldo, P.E. and Clementi, M. (1997) "Dynamic features of human immunodeficiency virus type 1 (HIV-1). Viremia, kinetics of cell-free HIV-1 RNA after therapeutic plasma exchange", Journal of Infectious Disease 176, 801-804.

Baum, S.E., Morris, J.T., Gibbons, R.V. and Cooper, R. (1999) "Reduction in human immunodeficiency virus patient hospitalizations and nontraumatic mortality after adoption of highly active antiretroviral therapy", Military Medicine 164, 609-612.

Beretta, A., Clerici, M., Hasson, H., Fumagalli, L., Trabattoni, D., Lillo, F., Ferrante, P., Saniabadi, A.R., Adachi, M. and Lazzarin, A. (2000) "Ex-vivo purging of circulating monocytes results in immunovirologic improvement in partially HAART responder HIV-infected patients", Journal of Biological Regulatory and Homeostatic Agents 14, 27-31.

Blick, G., Scott, W.F., Crook, S.W., Buchanan, S., Garton, T., Hopkins, U., Vadaboncoeur, A.M., Doolittle, J., Bulcraig, I.A., GreigerZanlungo, P. and Karpas, A. (1998) "Passive immunotherapy in advanced HIV infection and therapeutic plasmapheresis in asymptomatic HIV-positive individuals, a four-year clinical experience", Biotherapy 11, 7-14.

Blower, S.M., Aschenbach, A.N., Gershengorn, H.B. and Kahn, J.O. (2001) "Predicting the unpredictable: Transmission of drug-resistant HIV", Nature Medicine 7, 1016-1020.

Bonhoeffer, S., May, R.M., Shaw, G.M. and Nowak, M.A. (1997) "Virus dynamics and drug therapy", Proceedings of the National Academy of Sciences, USA 94, 6971-6976.

Bourinbaiar, A.S. (1994) "The ratio of defective HIV-1 particles to replication-competent infectious virions", Acta Virologica 38, 59-61.

Bower, M., Fox, P., Fife, K., Gill, J., Nelson, M. and Gazzard, B. (1999) "Highly active anti-retroviral therapy (HAART) prolongs time to treatment failure in Kaposi's sarcoma", AIDS 13, 2105-2111.

Bozzette, S.A. (2001) "Two studies of average life extension and HAART drug costs", New England Journal of Medicine 344, 817-831, $844-846$. 
Braunwald, E., Fauci, A.S., Kasper, D.L., Hauser, S.L., Longo, D.L. and Jameson, J.L. (2001) Harrison's Principles of Internal Medicine (McGraw-Hill, New York), 2629 pp.

Chaplin, J.W. (1999) "HIV pathogenesis: gp120-antibody complexes bind CD4 and kill T4 cells-immunotoxin therapy should preven the progression of HIV to AIDS", Medical Hypotheses $\mathbf{5 2}$ $133-146$.

Chun, T. and Fauci, A. (1999) "Latent reservoirs of HIV: obstacles to the eradication of virus", Proceedings of the National Academy of Sciences, USA 96, 10958-10961.

Chun, T-W., Davey, Jr., R.T., Engel, D., Lane, H.C. and Fauci, A.S. (1999) "Re-emergence of HIV after stopping therapy", Nature 401, 874-875.

Clifford, D.B., Yiannoutsos, C., Glicksman, M., Simpson, D.M., Singer, E.J., Piliero, P.J., Marra, C.M., Francis, G.S., McArthur, J.C., Tyler, K.L., Tselis, A.C. and Hyslop, N.E. (1999) "HAART improves prognosis in HIV-associated progressive multifocal leukoencephalopathy", Neurology 52, 623-625.

Cloyd, M.W., Chen, J.J. and Wang, I. (2000) "How does HIV cause AIDS? The homing theory", Molecular Medicine Today 6, 108-111.

Cohen, J. (2001) Shots in the Dark. The Wayward Search for an AIDS Vaccine (W.W. Norton and Co., New York), 384 pp.

Cohen, O.J., Kinter, A. and Fauci, A.S. (1997) "Host factors in the pathogenesis of HIV disease", Immunology Reviews 159, 31-48.

Cuatracasas, P., Wilchek, M. and Anfinsen, C.B. (1968) "Selective enzyme purification by affinity chromatography", Proceedings of the National Academy of Sciences, USA 61, 636-643.

Cussler, E. (1998) Diffusion: Mass Transfer in Fluid Systems (Cambridge University Press, Cambridge).

Davis, P. (1998) "FDA researchers model virus transport through synthetic barriers", Society for Industrial and Applied Mathematics News, 31

Fauci, A.S., Pantaleo, G., Stanley, S. and Weissman, D. (1996) "Immunopathogenic mechanisms of HIV infection", Annals of Internal Medicine 124, 654-663.

Fauci, A.S., Bartlett, J.G., Goosby, E.P., Kates, J. (2001). "Guidelines for the Use of Antiretroviral Agents in HIV-Infected Adults and Adolescents, February 2001". Panel on Clinical Practices for Treatment of HIV Infection, Department of Health and Human Services (DHHS), http://www.hivatis.org

Ferre, F., Moss, R.B., Daigle, A., Richieri, S.P., Jensen, F. and Carlo, D.J. (1995) "Viral load in peripheral blood mononuclear cells as surrogate for clinical progression", Journal of Acquired Immunodeficiency Syndrome and Human Retrovirology 10, S51-S56.

Furst, D., Felson, D., Thoren, G. and Gendreau, R.M. (2000) "Immunoadsorption for the treatment of rheumatoid arthritis: final results of a randomized trial. Prosorba Trial Investigators", Therapeutic Apheresis 4, 363-373.

Furtado, M.R., Callaway, D.S., Phair, J.P., Kunstman, K.J., Stanton, J.L., Macken, C.A., Perelson, A.S. and Wolinsky, S.M. (1999) "Persistence of HIV-1 transcription in peripheral-blood mononuclear cells in patients receiving potent antiretroviral therapy", New England Journal of Medicine 340(21), 1614-1622.

Gallo, R.C. and Schupbach, J. (2000) "Human retroviruses", In: Specter, S., Hodinka, R.L. and Young, S.A., eds, Clinical Virology Manua (ASM Press, Washington, DC), pp 513-549.

Gray, F., Adle-Biassette, H., Chretien, F., Lorin de la Grandmaison, G., Force, G. and Keohane, C. (2001) "Neuropathology and neurodegeneration in human immunodeficiency virus infection. Pathogenesis of HIV-induced lesions of the brain, correlations with HIV-associated disorders and modifications according to treatments", Clinical Neuropathology 20, 146-155.

Hauswirth, W., Lewin, A., Zolotukhin, S. and Muzyczka, N. (2000) "Production and purification of recombinant adeno-associated virus", Methods in Enzymology 316, 743-761.

Ho, D.D. (1995) "HIV-1 dynamics in vivo", Journal of Biological Regulatory and Homeostatic Agents 9, 76-77.

Ho, D.D., Neumann, A.U., Perelson, A.S., Chen, W., Leonard, J.M. and Markowitz, M. (1995) "Rapid turnover of plasma virions and CD4 lymphocytes in HIV-1 infection", Nature 373, 123-126.

Jardine, D.K., Tyssen, D.P. and Birch, C.J. (2000) "Effect of protease inhibitors on HIV-1 maturation and infectivity", Antiviral Research 45, 59-68.

Kameoka, M., Kimura, T., Zheng, Y.H., Suzuki, S., Fujinaga, K., Luftig, R.B. and Ikuta, K. (1997a) "Protease-defective, gp120-containing human immunodeficiency virus type 1 particles induce apoptosis more efficiently than does wild-type virus or recombinant gp120 protein in healthy donor-derived peripheral blood T cells", Journal of Clinical Microbiology 35, 41-47.

Kameoka, M., Suzuki, S., Kimura, T., Fujinaga, K., Auwanit, W., Luftig, R.B. and Ikuta, K. (1997b) "Exposure of resting peripheral blood T cells to HIV-1 particles generates CD25+ killer cells in a small subset, leading to induction of apoptosis in bystander cells", International Immunology 9, 1453-1462.

Kapadvanjwala, M. and Sofer, S. (1989) "A mathematical simulation of the AIDS patient and extracorporeal detoxification", Computers in Biology and Medicine 19, 461-470.

Kilby, J.M., Hopkins, S., Venetta, T.M., DiMassimo, B., Cloud, G.A., Lee, J.Y., Alldredge, L., Hunter, E., Lambert, D., Bolognesi, D., Matthews, T., Johnson, M.R., Nowak, M.A., Shaw, G.M. and Saag, M.S. (1998) "Potent suppression of HIV-1 replication in humans by T-20, a peptide inhibitor of gp41-mediated virus entry", Nature Medicine 4, 1302-1307.

Kiprov, D.D., Kwiatkowska, B.J. and Miller, R.G. (1990) "Therapeutic apheresis in human immunodeficiency virus-related syndromes", Current Studies in Hematology and Blood Transfusion 57, 184-197.

Koga, Y. (1996) "Apoptosis induction and its mechanism in HIV infection”, Nippon Rinsho 54, 1842-1847.

Krucker, T., Toggas, S.M., Mucke, L. and Siggins, G.R. (1998) "Transgenic mice with cerebral expression of human immunodeficiency virus type-1 coat protein gp120 show divergent changes in short- and long-term potentiation in CA1 hippocampus", Neuroscience 83, 691-700.

Kulkosky, J., Bouhamdan, M., Geist, A., Nunnari, G., Phinney, D.G. and Pomerantz, R.J. (2000) "Pathogenesis of HIV-1 infection within bone marrow cells", Leukemia and Lymphoma 37, 497-515.

Lafeuillade, A., Djediouane, A., Poggi, C., Profizi, N., Costes, O. and Tamalet, C. (1996a) "Kinetics of viral clearance in plasma, peripheral blood mononuclear cells and lymph nodes", AIDS 10, 801-802.

Lafeuillade, A., Poggi, C., Profizi, N., Tamalet, C. and Costes, O. (1996b) "Human immunodeficiency virus type 1 kinetics in lymph nodes compared with plasma", Journal of Infectious Diseases 174, 404-407.

Lawrence, J.E. (1993) "Affinity chromatography to remove viruses during preparation of plasma derivatives", Development of Biological Standards 81, 191-197.

Layne, S.P., Merges, M.J., Dembo, M., Spouge, J.L., Conley, S.R., Moore, J.P., Raina, J.L., Renz, H., Gelderblom, H.R. and Nara, P.L. (1992) "Factors underlying spontaneous inactivation and susceptibility to neutralization of human immunodeficiency virus", Virology 189, 695-714

Lipton, S. (1998) "Neuronal injury associated with HIV-1. Approaches to treatment", Annual Reviews of Pharmacology and Toxicology 38, $159-177$.

Little, S.J., McLean, A.R., Spina, C.A., Richman, D.D. and Havlir, D.V. (1999) "Viral dynamics of acute HIV-1 infection", Journal of Experimental Medicine 190, 841-850.

Lopukhin Iu, M., Pavlenko, V.V., Kulaev, D.V., Liukova, T.K., Petrunin, D.D., Karamov, E.V. and Rudneva, I.A. (1991) "Immunosorption of individual HIV proteins and virions", Vestnik Akademii Meditsinskikh Nauk SSSR 11, 60-63.

Lopukhin Iu, M., Pavlenko, V.V., Kulaev, D.V., Alekseichuk, V.S., Karamov, E.V., Rudneva, I.A., Petrunin, D.D. and Liukova, T.K. (1992) "Possibility of selective binding of HIV-1 infected cells by immunosorbents", Vestnik Rossiiskoi Akademii Meditsinskikh Nauk 3, 54-56.

Medina, I., Ghose, S. and Ben-Ari, Y. (1999) "Mobilization of intracellular calcium stores participates in the rise of $[\mathrm{Ca} 2+]_{i}$ and the toxic actions of the HIV coat protein GP120", European Journal of Neuroscience 11(4), 1167-1178.

Meinkoth, J. and Wahl, G. (1984) "Hybridization of nucleic acids immobilized on solid supports", Analytical Biochemistry 138 , 267-284.

Menzo, S., Bagnarelli, P., Monachetti, A., Fiorelli, L. and Clementi, M. (2000) "Complexity and dynamics of HIV-1 quasispecies", Journal of Biological Regulatory and Homeostatic Agents 14, 4-6.

Mocroft, A., Madge, S., Johnson, A.M., Lazzarin, A., Clumeck, N., Goebel, F.D., Viard, J.P., Gatell, J., Blaxhult, A. and Lundgren, J.D. (1999) "A comparison of exposure groups in the EuroSIDA study: starting highly active antiretroviral therapy (HAART), response to HAART, and survival", Journal of Acquired Immunodeficieny Syndrome 22, 369-378. 
Motomura, T., Miyashita, Y., Ohwada, T., Onishi, M. and Yamamoto, N. (1997). "Material for removing HIV and its related substances". US Patent 5,667,684

Muller, S. and Kohler, H. (1997) "B cell superantigens in HIV-1 infection", International Reviews in Immunology 14(4), 339-349.

Nair, M.P., Pottathil, R., Heimer, E.P. and Schwartz, S.A. (1988) "Immunoregulatory activities of human immunodeficiency virus (HIV) proteins: effect of HIV recombinant and synthetic peptides on immunoglobulin synthesis and proliferative responses by norma lymphocytes", Proceedings of the National Academy of Sciences, USA 85, 6498-6502.

Neumann, A.U., Tubiana, R., Calvez, V., Robert, C., Li, T.S., Agut, H., Autran, B. and Katlama, C. (1999) "HIV-1 rebound during interruption of highly active antiretroviral therapy has no deleterious effect on reinitiated treatment. Comet Study Group", AIDS 13, 677-683.

Nygren, H., Werthen, M. and Stenberg, M. (1987) "Kinetics of antibody binding to solid-phase-immobilised antigen. Effect of diffusion rate limitation and steric interaction", Journal of Immunological Methods 101, 63-71.

O'Brien, W.A., Hartigan, P.M., Martin, D., Esinhart, J., Hill, A., Benoit, S., Rubin, M., Simberkoff, M.S. and Hamilton, J.D. (1996) "Changes in plasma HIV-1 RNA and CD4+ lymphocyte counts and the risk of progression to AIDS. Veterans Affairs Cooperative Study Group on AIDS", New England Journal of Medicine 334, 426-431.

Ogg, G.S., Jin, X., Bonhoeffer, S., Dunbar, P.R., Nowak, M.A., Monard, S., Segal, J.P., Cao, Y., Rowland-Jones, S.L., Cerundolo, V., Hurley, A., Markowitz, M., Ho, D.D., Nixon, D.F. and McMichael, A.J. (1998) "Quantitation of HIV-1-specific cytotoxic T lymphocytes and plasma load of viral RNA", Science 279, 2103-2106.

Pearce-Pratt, R. and Phillips, D.M. (1993) "Studies of adhesion of lymphocytic cells: implications for sexual transmission of human immunodeficiency virus", Biology of Reproduction 48(3), 431-445.

Ramratnam, B., Bonhoeffer, S., Binley, J., Hurley, A., Zhang, L., Mittler, J.E., Markowitz, M., Moore, J.P., Perelson, A.S. and Ho, D.D. (1999) "Rapid production and clearance of HIV-1 and hepatitis C virus assessed by large volume plasma apheresis", Lancet 354, 1782-1785.

Ramratnam, B., Mittler, J.E., Zhang, L., Boden, D., Hurley, A., Fang, F. Macken, C.A., Perelson, A.S., Markowitz, M. and Ho, D.D. (2000) "The decay of the latent reservoir of replication-competent HIV-1 is inversely correlated with the extent of residual viral replication during prolonged anti-retroviral therapy", Nature Medicine 6, 82-85.

Saha, D. and Agarwal, S. (2001) "Hepatitis and HIV infection during haemodialysis", Journal of the Indian Medical Association 99(4), 194-202.

Scamurra, D., Ambrus, J. (1999). "Method for removal of HIV and other viruses". US Patent Application 60/098,477; PCT/US 99-19448.

Schnittman, S.M., Lane, H., Higgins, S.E., Folks, T. and Fauci, A. (1986) "Direct polyclonal activation of human B-lymphocytes by the acquired immune deficiency syndrome virus", Science 233(4786), $1084-1086$.

Schnittman, S.M., Psallidopoulos, M.C., Lane, H.C., Thompson, L., Baseler, M., Massari, F., Fox, C.H., Salzman, N.P. and Fauci, A.S. (1989) "The reservoir for HIV-1 in human peripheral blood is a T cell that maintains expression of CD4", Science 245, 305-308.

Stafford, M.A., Corey, L., Cao, Y., Daar, E.S., Ho, D.D. and Perelson, A.S. (2000) "Modeling plasma virus concentration during primary HIV infection", Journal of Theoretical Biology 203, 285-301.

Su, Q., Wang, S.F., Chang, T.E., Breitkreutz, R., Hennig, H., Takegoshi, K., Edler, L. and Schroder, C.H. (2001) "Circulating hepatitis B virus nucleic acids in chronic infection: representation of differently polyadenylated viral transcripts during progression to nonreplicative stages", Clinical Cancer Research 7(7), 2005-2015.

Takashima, S.K., Keiichi, N., Nakaji, S., Yamane, K., Murayama, R. (1991). "Method for removing human immunodeficiency virus and/or its related compounds". US Patent 5,041,079.

Tepic, S., Laissue, J.A. (1996). "An extracorporeal blood treatment apparatus and method for removal of free circulating infectious agents based on immobilized CD4 receptors". Patent Application WO96 28198.

Terman, D. S., Sulliva, M., Cullis, H.M. (1980). "Apparatus for the extracorporeal treatment of disease". US Patent 4,215,688.

Tuckwell, H.C. and Le Corfec, E. (1998) "A stochastic model for early HIV-1 population dynamics", Journal of Theoretical Biology 195, $451-463$.

Wang, H., Tsao, I. (1988). "Cellular receptor adsorbents for removal of viral contaminants from blood and complex protein solutions". Patent Application WO8901813A1.

Wei, X., Ghosh, S.K., Taylor, M.E., Johnson, V.A., Emini, E.A., Deutsch, P., Lifson, J.D., Bonhoeffer, S., Nowak, M.A. and Hahn, B.e.a. (1995) "Viral dynamics in human immunodeficiency virus type 1 infection", Nature 373, 117-122.

Wiegers, K., Rutter, G., Kottler, H., Tessmer, U., Hohenberg, H. and Krausslich, H.G. (1998) "Sequential steps in human immunodeficiency virus particle maturation revealed by alterations of individual Gag polyprotein cleavage sites", Journal of Virology $\mathbf{7 2}$, 2846-2854.

Winston, J. and Klotman, P.E. (1998) "HIV-associated nephropathy", Mount Sinai Journal of Medicine 65, 27-32.

Wodarz, D., Lloyd, A.L., Jansen, V.A. and Nowak, M.A. (1999) "Dynamics of macrophage and T cell infection by HIV", Journal of Theoretical Biology 196, 101-113.

Zhang, L., Ramratnam, B., Tenner-Racz, K., He, Y., Vesanen, M., Lewin, S., Talal, A., Racz, P., Perelson, A.S., Korber, B.T., Markowitz, M. and Ho, D.D. (1999) "Quantifying residual HIV-1 replication in patients receiving combination antiretroviral therapy", New England Journal of Medicine 340, 1605-1613. 


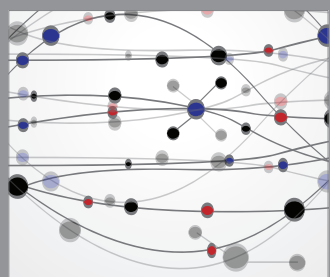

The Scientific World Journal
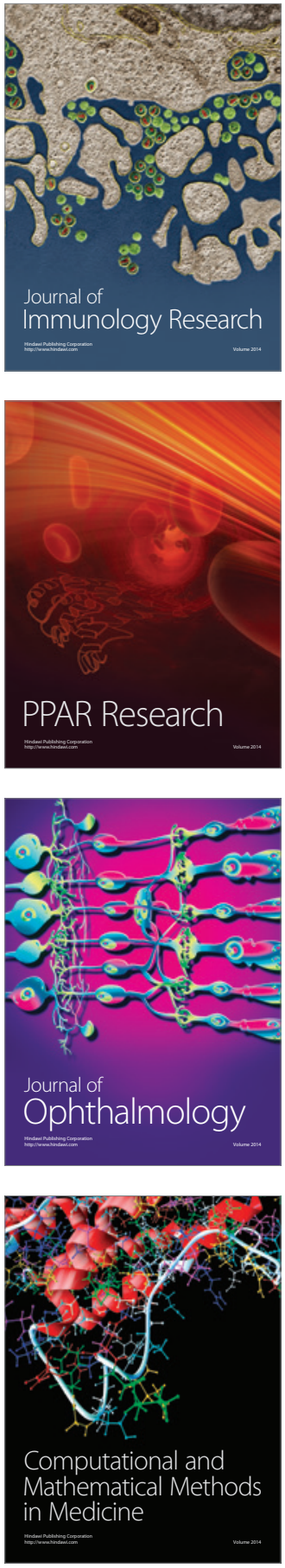

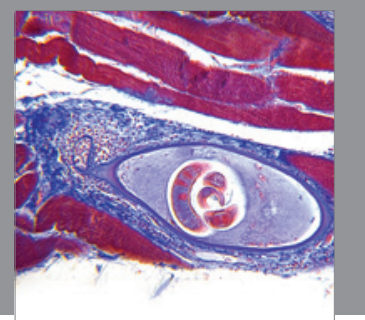

Gastroenterology

Research and Practice
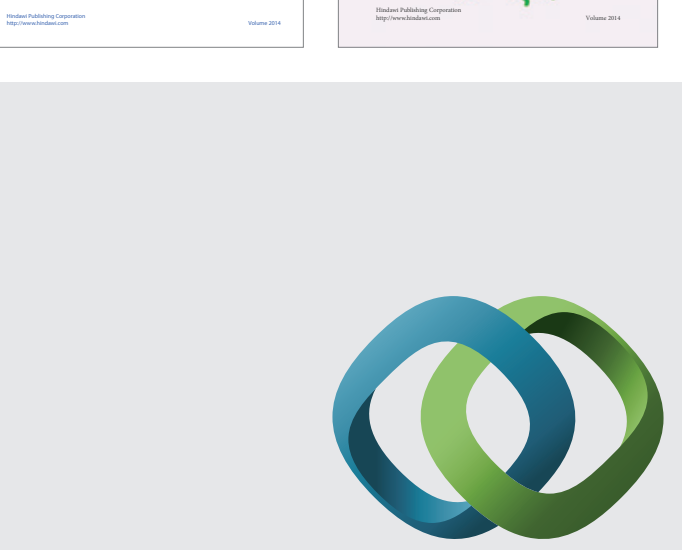

\section{Hindawi}

Submit your manuscripts at

http://www.hindawi.com
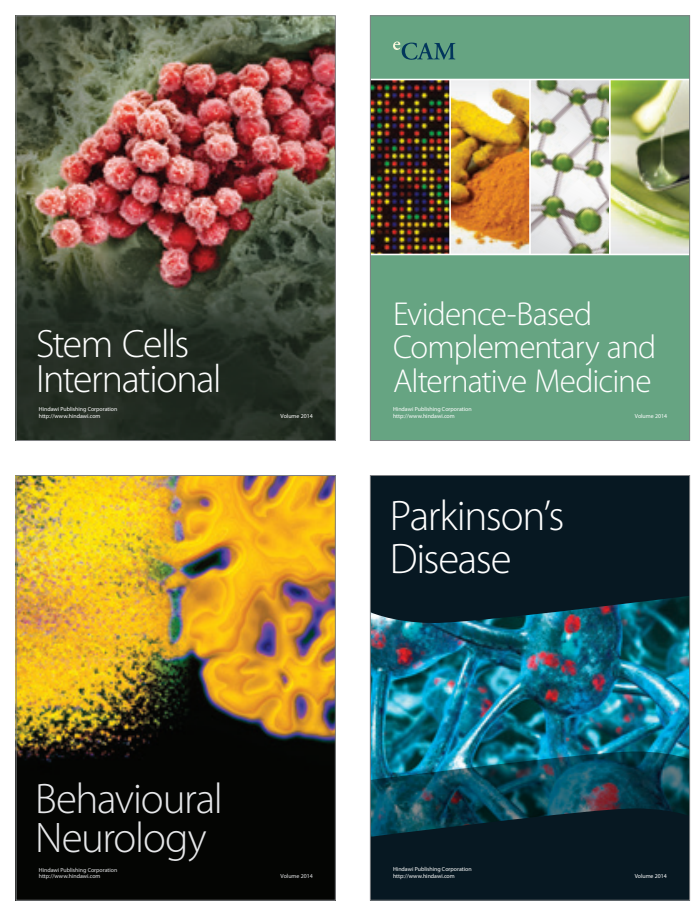

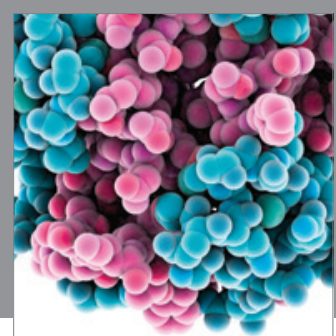

Journal of
Diabetes Research

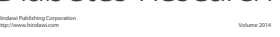

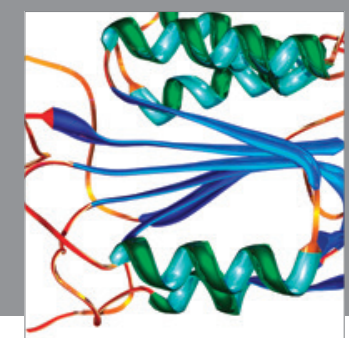

Disease Markers
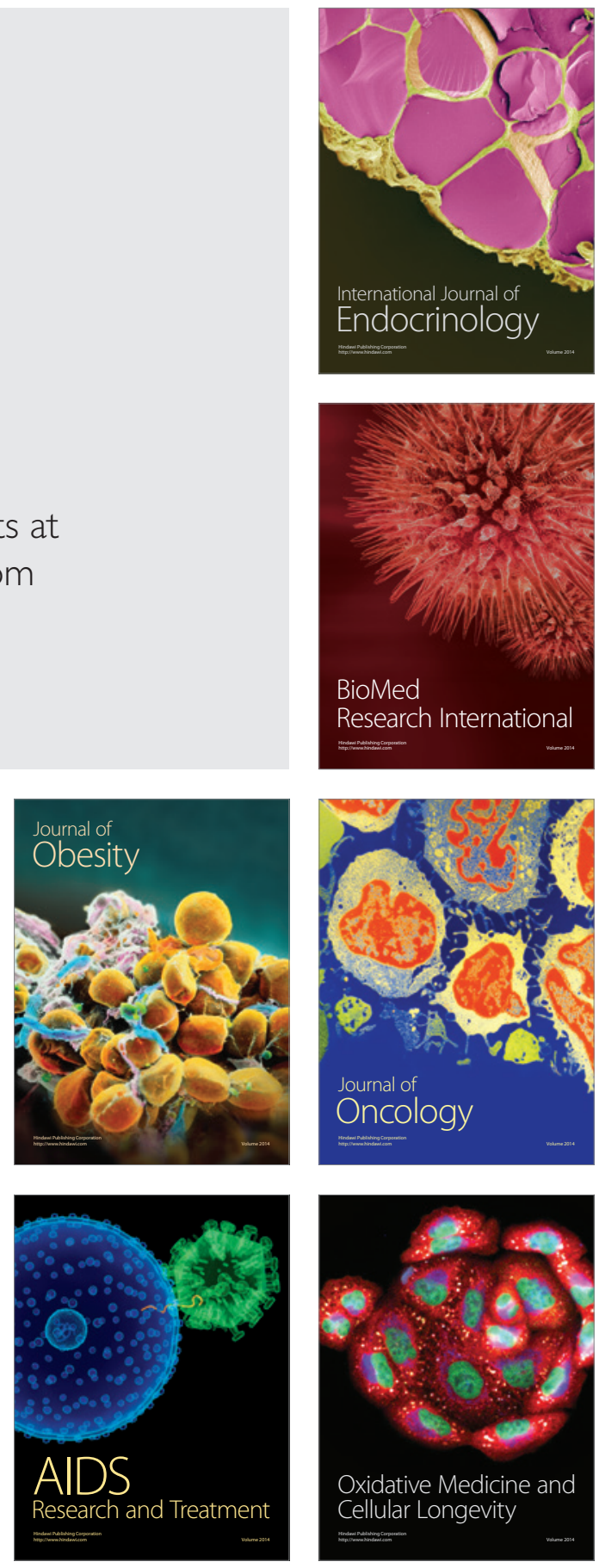